\title{
All-terrain Vehicle (ATV) Safety at Work
}

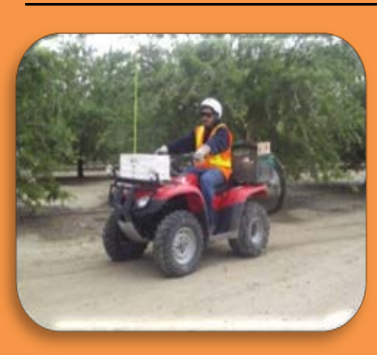

\section{Facts Related to ATV Crashes and Injures at Work ${ }^{1}$}

- Males are at a much higher risk

- Workers 65 years of age or older are at higher risk than younger workers

- Rollovers are the most common cause of crashes

- Animal production workers have the highest risk for injury

Note: This document does not apply to Utility Vehicles (UTVS)

\section{Background}

ATVs were first introduced in the U.S. for agricultural use in the early 1980s. Over the past thirty years, ATVs have grown increasingly popular recreationally and more recently, have become a valuable asset at work. With more than 10 million in use, it is important to know the hazards associated with ATVs and how to operate them safely. ${ }^{1,2}$

Recommended Practices for the Safe Use of ATVs at Work ${ }^{3-5}$

\section{FOR EMPLOYERS}

- Provide helmet and eye-protection for workers and encourage the use of other personal protective equipment (PPE)

- Identify and mark - and eliminate if possible - hazards such as excavations, trenches, and guy wires that might be present in specific work environments, so they are easily seen and avoided by workers on the job site

- Establish operating and maintenance policies that follow manufacturer's terrain guidelines, specified hauling and towing capacity, and passenger restrictions

- Provide employees access to hands-on training by an ATV Safety Institute instructor or a similarly qualified instructor

- Share responsibility with employees on the practices detailed below

\section{FOR EMPLOYEES}

- Wear PPE including a helmet, eye-protection, long pants, and sturdy boots

- Participate in hands-on training in the safe handling and operation of an ATV

- Conduct a pre-ride inspection of tires, brakes, headlights, etc., and follow employer's maintenance polices for upkeep of the ATV

- Understand how implements and attachments may affect the stability and handling of the ATV

- Never exceed the manufacturer's specified hauling and towing capacity or weight limits and ensure cargo is balanced, secured, and loaded on provided racks

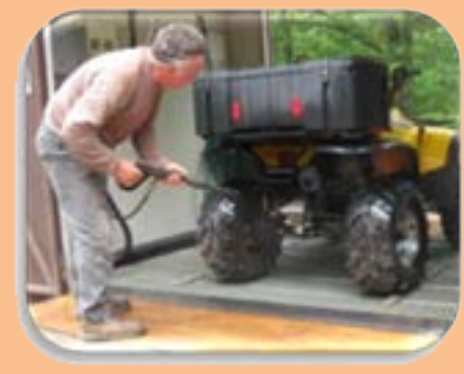

- Be aware of potential hazards such as trees, ruts, rocks, streams and gullies, and follow posted hazard warnings

- Drive at speeds safe for weather and terrain and never operate ATVs on surfaces not designed for ATVs such as paved roads and highways

- Never permit passengers on the ATV, unless the ATV has an additional seat specifically designed to carry them

- Never operate an ATV while under the influence of drugs or alcohol 
Common Work Related Uses of ATVs

- Border patrol and security

- Construction operations

- Emergency medical response

- Land management and surveying

- Law enforcement

- Military operations

- Mineral and oil exploration, pipeline maintenance

- Ranching and farming

- Search and rescue

- Small-scale forestry activities

- Wildland fire control

\section{Did You Know?}

ATVs have unique features that enable them to operate in harsh work environments where larger, less mobile vehicles cannot safely be used. Their oversized, deep tread, and low-pressure tires (4-5 psi) and light weight (600-1000 pounds) - compared to other motorized vehicles - enhance their maneuverability but also present risks such as a rollover which may occur due to a high center of gravity and a relatively narrow wheelbase.

\section{ONLINE RESOURCES}

- Agricultural Safety and Health Council of America: http://www.ashca.com

- ATV Safety Institute: http://www.atvsafety.org/InfoSheets/ATV_Riding_Tips.pdf; https://online.svia.org/training/default.aspx

- Farm Safety 4 Just Kids: http://www.fs4jk.org

- National Children's Center for Rural Agricultural Health and Safety: http://www.marshfieldclinic.org/nccrahs

- National Education Center for Agricultural Safety: http://www.necasag.org

To receive documents or other information about occupational safety and health topics, contact NIOSH at: $\mathbf{\square}$ Telephone: $1-800$ CDC-INFO (1-800-232-4636); TTY: 1-888-232-6348 — E-mail: cdcinfo@cdc.gov, a or visit the NIOSH web site at: www.cdc.gov/niosh

For a monthly update on news at NIOSH, subscribe to NIOSH eNews by visiting www.cdc.gov/niosh/eNews

\section{This document is in the public domain and may be freely copied and reprinted.}

Mention of any company or product does not constitute endorsement by NIOSH. In addition, citations to Web sites external to $\mathrm{NIOSH}$ do not constitute NIOSH endorsement of the sponsoring organizations or their programs or products. Furthermore, NIOSH is not responsible for the content of these Web sites.

\section{References}

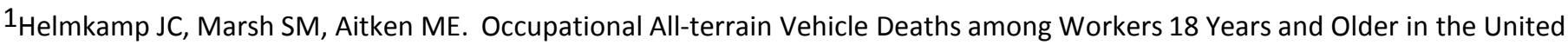
States, 1992-2007. J Ag Safety and Health 2011; 17(2):147-152. Available at: http://www.ncbi.nlm.nih.gov/pubmed/21675284 ${ }^{2}$ Garland, S. Annual Report of ATV-related Deaths and Injuries: December 2011. Bethesda, MD: U.S. Consumer Product Safety Commission, Directorate for Epidemiology. Available at: http://www.cpsc.gov/library/foia/foia12/os/atv2010.pdf

3U.S. Consumer Product Safety Commission. ATV Safety Messages. Available at: http://www.atvsafety.gov/safetytips.html

${ }^{4}$ U.S. Department of Labor, Occupational Safety and Health Administration. Hazards Associated with All-terrain vehicles (ATVs) in the Workplace. Safety and Health Information Bulletin 08-03-2006. Available at: http://www.osha.gov/dts/shib/shib080306.html

${ }^{5}$ U.S. Department of Labor, Safety and Health in the Workplace: Drug-free Workplaces. Available at: http://www.dol.gov/compliance/topics/safety-health-working-partners.htm 